\title{
La publicidad de salud en la prensa ilustrada de finales del siglo XIX
}

Ma Dolores Fernández Poyatos | dolores.fernandez@ua.es

Universidad de AlicANTE

Resumen: A finales del siglo XIX, la publicidad de las medicinas patentadas fue vital para el desarrollo de la prensa y la evolución de la actividad publicitaria, en los primeros países en industrializarse. Dada la inexistencia de estudios sobre este tema en España, se plantea la hipótesis de que hubo de existir un proceso similar. El estudio se centra en el análisis de un corpus de anuncios aparecidos desde 1891 a 1899 en el semanario ilustrado Blanco y Negro. El objetivo es comprobar el peso de este sector, así como describir las distintas formas galénicas y el tipo de especialidad que primaba.

Palabras clave: publicidad, salud, medicinas patentadas, revista

Abstract: At the end 19th century, the advertising of patent medicines was vital for the development of the press and the evolution of the advertising activity, in the first industrialized countries. Given the inexistence of studies about this issue in Spain, it is presented the hypothesis about the existence of a similar process. The investigation is focused on the analysis of a group of advertisements appeared from 1891 to 1899 in the illustrated weekly magazine Blanco y Negro. The objective is verifying the weight of this sector, as well as describing the different galenic forms and the kind of specialization that predominated.

Key words: advertising, health, patent medicines, magazine 


\section{Introducción}

\subsection{Economía española}

Desde la tesis de Nadal (1975) acerca del fracaso de la revolución industrial en España, pocos temas han suscitado tanta controversia y atención. Los resultados más representativos de una polémica que aún perdura pueden sintetizarse de la siguiente forma (Martínez Carrión, 2000: 72-87). En primer lugar, la tesis de Nadal acerca del fracaso descansa en varias razones, entre ellas ocupan un lugar preferente los problemas de la demanda derivados del atraso del sector agrícola y de su baja productividad. La población española, campesina en su mayoría y de escasos recursos, poseía un bajo nivel de consumo de productos industriales y un exiguo grado de bienestar.

En contraposición, las dificultades padecidas por la industria en España hay que buscarlas, más que en la demanda, en los factores de la oferta; es decir, los problemas de la industria habría que investigarlos dentro de ella misma: la insuficiente capacidad para exportar de la industria fue consecuencia de su bajo nivel de productividad (Prados, 1988 y Tortella, 1994). Son las llamadas tesis endogenistas, que explican los problemas padecidos por la economía española, entre 1800 y 1936, desde dentro (Martínez Carrión, 2000: 77).

Por último, Prados (1995) y Carreras (1997: 35-60) sostienen, primero, que el crecimiento económico español entre los siglos XIX y XX fue menos intermitente de lo que con anterioridad se creía; y segundo, que la economía española, si bien descendió vertiginosamente desde los primeros años del siglo XIX hasta finales de 1860, creció con moderación entre mediados de siglo y 1913, continuando, después, en una línea mantenida hasta 1930. Esto es, una economía que creció tímidamente por el escaso desarrollo industrial, pero también por las repetidas crisis de subsistencia -1856, 1868, 1879, 1882, 1887-, por las continuas epidemias - cólera, tifus, sarampión...- y por las "enfermedades infectocontagiosas endémicas derivadas de una nutrición deficiente $y / 0$ de la insalubridad y producto, por lo tanto, del atraso económico y de la escasa provisión de bienes preferentes por el estado" (Escudero y Simón, 2003: 539-540), que provocaron la permanencia hasta 1900 del sistema demográfico tradicional -altas tasas de mortalidad y corta esperanza de vida-. Los últimos trabajos antropométricos ${ }^{1}$ sobre la evolución de la población española confirmarían este crecimiento demográfico modesto (2003: 530). Precisamente, los estudios antropométricos, abundantes durante el siglo XIX, fueron impulsados por médicos higienistas.

\footnotetext{
${ }^{1}$ La antropometría considera la estatura como un indicador para medir el bienestar de los países.
} 


\subsection{Las corrientes higienistas}

Entre las transformaciones sociales del siglo, y en concreto en el ámbito de la medicina y la salud, destacan las innovaciones que, derivadas de la Ilustración, se plasmaron en el progreso de las ideas científicas y en la preocupación por las enfermedades y epidemias que se cebaban sobre la población, así como por las soluciones o medidas preventivas contra ellas. Es lo que se conoce como doctrina higienista. La importancia de su función e ideario quedó plasmada en numerosas publicaciones periódicas (920 títulos) y no periódicas (7.333 títulos), que vieron la luz entre 1763 y 1939. Aumento que se explica tanto por el avance de las conquistas sociales, como por las innovaciones científicas en los países europeos (Alcaide, 1999a: 2-6).

En España, se distinguen dos momentos en la difusión del higienismo. El primero, activo, fundamentado en las reformas iniciadas por los miembros de la comunidad científica. El segundo, pasivo, de recepción y aceptación por parte de la población a la que se dirigían tales reformas y que tuvieron en la ciudad "el escenario idóneo donde empezar a poner en práctica [...] medidas encaminadas a prevenir y erradicar las epidemias" (1999b: 29). Tres ciudades comparten las aplicaciones prácticas del higienismo: Madrid, Barcelona y Valencia. Entre las causas que lo explican, destacan: 1) La existencia de facultades de medicina y la propagación del conocimiento científico y 2) La concentración humana en ínfimas condiciones de higiene y alimentación provocaba en las ciudades un índice de mortalidad mayor que el de las áreas rurales. Durante esta época, los centros urbanos, y sobre todo la clase fabril, fueron los focos más afectados por epidemias y enfermedades. Pero además, esta población, dada su falta de medios, se vio afectada más que otros colectivos por las denominadas enfermedades sociales típicas: "La infección hace estragos entre las clases bajas y deja bastante incólumes a los núcleos privilegiados" (Nadal, 1975: 159).

El movimiento higienista español, representado por Seoane, Monlau y Méndez Álvaro, conformó el primer proyecto de nuestro país; sus actividades hicieron posible una toma de conciencia respecto a la necesidad de un cambio social que había de abarcar, tanto el aspecto de la enfermedad que entrañaba una mejora de la calidad de vida, como la obtención de derechos considerados fundamentales por parte de las clases más desfavorecidas. La lucha de los higienistas se libró en dos frentes: en el de la investigación científica y en el diseño de un nuevo concepto de la ciudad y de sus habitantes. Gracias a ellos, la sociedad se encaminó hacia la obtención de uno de sus bienes más preciados: la salud (Alcaide, 1999b: 30-31). Y si la preocupación por la salud quedó reflejada en los idearios médicos, también quedó plasmada en la publicidad. 


\subsection{Publicidad, salud y específicos}

La primigenia labor de los pioneros publicitarios en Gran Bretaña -White, Barker, Deacony en Estados Unidos - Kennedy, Rowell y Powers - estuvo muy vinculada al sector de las medicinas patentadas. De ellas, proviene parte del descrédito que la publicidad se granjeó en sus inicios; sin embargo, estas medicinas influyeron positivamente en su historia por varios motivos: 1) Ayudaron a los agentes publicitarios a regularizar sus tarifas e identificar los lugares donde se anunciaban; 2) La mitad de los ingresos de las agencias provenía de dichos productos y 3 ) La publicidad de las medicinas patentadas aportó tales ingresos a las revistas que les permitió superar la precaria existencia que hasta entonces las había caracterizado (Eguizábal, 1998: 221-222). Gracias a esto, las revistas pasaron en treinta años a ser entendidas como un poderoso soporte publicitario.

A finales del siglo XIX en Estados Unidos, las revistas más prestigiosas incluían más anuncios de medicinas patentadas que de otros sectores y sólo a partir de 1889 los anuncios de muebles y equipamiento para el hogar lograron superar a los de medicinas patentadas (Norris, 1990: 48). Sabedores de las consecuencias que la relación con estos anunciantes podía tener sobre su trabajo, las más afamadas agencias de publicidad fomentaron el rechazo hacia ellos. N. W. Ayer \& Son canceló cuentas y decidió no aceptar ninguna publicidad que tuviera afirmaciones extravagantes o que remediasen el asma, la bronquitis, la gripe, etc. (Norris, 1990: 49-50).

La trayectoria de Ayer \& Son fue representativa del proceder de otras conocidas agencias: si entre 1877 y 1878, las medicinas habían encabezado la lista de clientes de Ayer (aproximadamente dos tercios de sus ingresos -el 21,6\%-), entre 1900 y 1901, los anuncios de medicinas patentadas se habían reducido una quinta parte $(8,39 \%)$.

\footnotetext{
Al mismo tiempo, los gastos totales de la agencia en espacio publicitario se habían incrementado aproximadamente en un $1000 \%$ (de 317.148 a 3.366.803). Treinta años después, se incrementan cerca del mismo porcentaje (hasta 38.068.734) en anuncios totales, siendo los de automóviles, neumáticos y accesorios los que encabezaban la lista, seguidos de tabaco, comida y bebidas, medicinas y artículos de tocador para componer dos tercios del negocio de la agencia (Norris, 1990: 50).
}

Se aprecia, no sólo la pérdida de la ventajosa posición de las medicinas en la industria publicitaria -lógica consecuencia del descrédito social-, sino también el crecimiento experimentado por unos bienes de consumo que se encargarían de ocupar, a partir de entonces, el espacio publicitario en revistas y periódicos. En muchos casos, estos nuevos artículos han mantenido hasta nuestros días un prominente y aventajado lugar; pero lo más sobresaliente, al margen del impresionante crecimiento de la publicidad, iba a ser desde entonces su utilización para introducir nuevos productos, para homogeneizar gustos y para incrementar la demanda. 


\subsection{La prensa ilustrada}

Aunque los primeros semanarios ilustrados nacen en España a mediados del siglo XIX, no es hasta 1869 con la aparición de La Ilustración Española y Americana y hasta 1870 con la creación de La Ilustración de Madrid, cuando se logra una calidad excepcional. Los dos respondían a fórmulas casi idénticas; de periodicidad semanal e independencia política, fueron magníficas revistas de grabados y dibujos que se ocuparon poco de la actualidad nacional; combinaron la información contemporánea con la divulgación de temas artísticos, literarios, históricos y científicos; no en vano, dieron cabida en sus páginas a notables plumas como Pi y Margall, Bécquer, Galdós, y también a excelentes colaboradores gráficos: Ortego, Perea, etc.

A finales de siglo, la introducción del grabado en color y del reportaje fotográfico transformó radicalmente la prensa ilustrada. En 1891, nace Blanco y Negro con un concepto más periodístico y ágil que el de La Ilustración Española y Americana (Seoane, 1992: 308). Mucho más barata, Blanco y Negro fue ideada con un planteamiento comercial moderno. Su éxito fue fulminante: en el segundo número vendió 25.000 ejemplares que rápidamente aumentaron, así como la "aceptación en sus páginas de anuncios ilustrados, convirtiendo a la revista en un negocio muy rentable" (1992: 309). En su fórmula armonizaba lo literario, con lo recreativo e informativo; en julio de 1898, alcanzó una tirada récord de 70.000 ejemplares. Aunque pronto tuvo un rival, Nuevo Mundo, que fundada en 1894 por José del Perojo le llegó a superar en ventas a principios del siglo XX. La competencia entre los dos semanarios desembocó en una airada polémica sobre la veracidad de sus tiradas que desveló la naturaleza de soporte publicitario que la prensa ilustrada reclamaba (Fernández Poyatos, 2006: 195-203).

Tras las disputas protagonizadas en 1880 y 1885 por los periódicos de Madrid a propósito del timbre y los datos de tirada (Castillo, 1975: 149-198), la mantenida entre Blanco y Negro y Nuevo Mundo revela el papel de estas publicaciones como puntales de una evolución que ya no se detendría. En sus páginas abundan testimonios que avalan esta estrategia comercial, evidenciada en las polémicas de la prensa sobre el asunto publicitario:

\footnotetext{
Porque todo diario que no acepta subvenciones del poder, que rechaza todo género de favores de las empresas financieras, grandes ó chicas, y que lleva sus honrados escrúpulos hasta omitir opiniones y juicios en todos aquellos casos que puedan servir a intereses meramente particulares, necesita elementos de vida propia, y éstos, en un país como el nuestro, donde la prensa es baratísima para los suscritores [...] no pueden ser otros que los ingresos de publicidad por medio del anuncio. (El Imparcial, 28-7-1885: 2).

Vivimos del favor del público, y bajo el aspecto material del anunciante tanto como del suscritor [...]. Nos complacemos de ser en esto como los grandes periódicos independientes de Inglaterra y Alemania (El Imparcial, 28-7-1885: 2).
}

Como líricamente expresó Altabella en estos años "surgió el anuncio, el imperio naciente de la publicidad, manifestada tibiamente en la 'cuarta plana', y después en las restantes hasta asaltar, señora, la primera" (1963: 17). Aunque también, y desde luego con menos lirismo, estos documentos traslucen la necesidad de financiación que, a través de la publicidad, tenía la prensa. 


\section{Metodología}

Dada la importancia que la publicidad de medicamentos milagrosos tuvo en el nacimiento de la publicidad moderna en los first comers ${ }^{2}$ (Gran Bretaña, Estados Unidos, Francia, Alemania, Bélgica), y dada la escasez de investigaciones sobre ello en España, nuestro objetivo se ha centrado en verificar y cuantificar su presencia durante la última década del siglo XIX. La constatación de esta influencia en estos países nos anima a plantear la hipótesis de que también en España la publicidad de específicos fue vital para el desarrollo de la prensa, así como para evolución de la publicidad (Checa, 2007: 81).

Para la recopilación y selección de anuncios, hemos analizado el semanario Blanco y Negro desde 1891 hasta 1899. El año 1891 corresponde a su nacimiento; el de 1899, al cierre del siglo. La muestra de estudio se compone de mil trescientos sesenta y seis anuncios. Asimismo, para confirmar o refutar la información hemos revisado veinte ejemplares de la revista Nuevo Mundo publicados entre 1895 y 1899.

En lo que concierne a la fijación de sectores, la categorización que desarrollamos no es de consumo en general, sino de consumo de productos susceptibles de ser anunciados en el período estudiado, pues son los que experimentan un aumento de su demanda conforme se incrementa la renta, es decir, en función de la Ley de Engel; de acuerdo con ella, el porcentaje del presupuesto familiar destinado a gasto en alimentación disminuye a medida que aumenta la renta. Es así como la saturación de anuncios de medicinas, o la escasa presencia de la publicidad de seguros y finanzas, puede, cuando menos, entenderse.

También hemos desechado las tipologías de uso actual en el ámbito publicitario, porque están adaptadas a los vigentes sectores de producción y comercialización y éstos no son los de hace más de cien años. En la de Infoadex, por ejemplo, sectores como deporte, energía, cultura y medios de comunicación no son significativos en la España del siglo XIX; otros, como telecomunicaciones e Internet, ni siquiera existían. A tenor de lo dicho, la clasificación propuesta es la que figura en el cuadro 1.

En lo que respecta al sector Salud, y debido a que sólo nos interesan las clasificaciones de naturaleza publicitaria, partimos de la propuesta por Pérez Ruiz, quien distingue entre publicidad de productos, de comerciantes y de diseño de marcas (2001: 28-33). En la primera, los anuncios son básicamente textuales, con figuras sencillas que actúan de "elemento de referencia" (2001: 28); la segunda busca, ante todo, informar del nombre y dirección de los comercios, géneros y clientes a los que se dirigen; la tercera recoge la aportación de los artistas a la marca y a las etiquetas publicitarias.

Sin embargo, es preciso aclarar que si bien nuestra hipótesis de trabajo es similar a la de Pérez Ruiz, y por lo tanto su clasificación resulta genéricamente válida, la investigación realizada nos lleva a proponer otra. Dicho de otra forma, aunque por la vía hipotético-

\footnotetext{
${ }^{2}$ Se emplea en economía para adjetivar los primeros países que se industrializaron.
} 
deductiva podamos llegar a parecidas o idénticas conclusiones, por la vía inductiva, es decir, a través del descubrimiento y del análisis de un corpus de mil trescientos sesenta y seis anuncios, vamos a obtener unos resultados con más matices.

De una parte, hemos mantenido el primer y segundo grupo, hemos desechado el tercero y, de otra, hemos añadido uno nuevo: la publicidad de servicios. Proceder que se justifica porque el análisis del corpus de anuncios reveló que, efectivamente, se podía elaborar una catalogación de productos y comerciantes, aunque a esta última hemos preferido denominarla publicidad de establecimientos. Respecto del diseño de marcas, varias razones han motivado su exclusión: primero, resultaba muy complicado encontrar elementos en común para trabajarla en relación a los otros grupos; segundo, atender a la caracterización de la publicidad desde un punto de vista formal (uso y desarrollo de la imagen), suponía considerar este criterio para un único grupo, lo que, creemos, provocaba una pérdida de cohesión.

La introducción de una nueva categoría - servicios - tiene una explicación similar al primer caso, esto es, el examen de los anuncios reveló la existencia de contenidos diferentes a los de productos y establecimientos. Así pues, la clasificación que proponemos es la siguiente:

1) Publicidad de productos: el objeto del mensaje es la mercancía. El mensaje gira en torno a la mercancía, se refiere a ella.

2) Publicidad de establecimientos: lo importante aquí es informar sobre la dirección, el tipo de comercio y los artículos que se venden.

3) Publicidad servicios: aquélla en la que un individuo da a conocer, ofreciéndola al público, su profesión y trabajo.

\section{Resultados}

Lo que de inmediato llama la atención en Blanco y Negro es la abundancia de anuncios de medicinas patentadas o específicos, nombre utilizado desde 1892 hasta 1919, cuando fue sustituido por el de especialidades farmacéuticas, "reconocido y autorizado por sanidad" (García Gutiérrez, 1990: 13). Y no sólo en la revista aludida, sino también en Nuevo Mundo, así como en periódicos de la capital o de provincias, donde es posible apreciar, a simple vista, el amplio espacio que esta publicidad ocupaba.

Tras el análisis del corpus, el sector con más peso es el de Salud -34,82\%-, lo que significa más de un tercio de los anuncios de la revista. A continuación, se sitúan Hogar (15,30\%), Consumo Suntuario (14,78\%) y Belleza (13,39\%). Alimentación alcanza un peso del $10,02 \%$. Los dos siguientes - Maquinaria industrial (4,46\%) y Automoción $(2,70 \%)-$ obtienen una representación pequeña, que llega a ser insignificante en el caso de Seguros y finanzas $(0,51 \%)$ y Transportes, viajes y turismo $(0,36 \%)$. En el sector Varios, integrado por 
63 anuncios $(4,61 \%)$, se han incluido productos diversos como azulejos, pegamentos, academias, cemento, cuya representación es anecdótica.

Cuadro 1. Distribución de publicidad por sectores

\begin{tabular}{|l|l|l|}
\hline Sectores Anunciantes & No Anuncios & $\begin{array}{l}\text { Tasa } \\
\text { participación }\end{array}$ \\
\hline Salud & 462 & 34,82 \\
\hline Hogar & 209 & 15,30 \\
\hline Consumo suntuario & 202 & 14,78 \\
\hline Belleza & 183 & 13,39 \\
\hline Alimentación & 137 & 10,02 \\
\hline Maquinaria industrial & 61 & 4,46 \\
\hline Automoción & 37 & 2,70 \\
\hline Seguros y finanzas & 7 & 0,51 \\
\hline Transportes, viajes, turismo & 5 & 0,36 \\
\hline Varios & 63 & 4,61 \\
\hline Total anuncios & 1366 & \\
\hline
\end{tabular}

Elaboración propia a partir del corpus de anuncios de Blanco y Negro (1891-1899).

Dos causas explicarían el claro predominio de publicidad de la salud. Primero, hay demanda de este tipo de productos porque se quiere aumentar la esperanza de vida. En la España de finales de siglo, la media de edad se situaba alrededor de los cuarenta años. En segundo lugar, y desde el factor oferta, entendemos que debe darse la circunstancia de que había bastantes empresas compitiendo por esos productos porque si no, no hubiera habido incentivos para gastar en publicidad. Hoy en día, por limitaciones legales, apenas existe publicidad de medicamentos y de servicios médicos, excepción hecha de las revistas del sector, utilizando las empresas farmacéuticas otros procedimientos para dar a conocer sus productos como son los visitadores médicos, las acciones de relaciones públicas o las promociones.

Los avances científicos en el ámbito farmacéutico a principios del siglo XIX provocaron la salida de la preparación e investigación de los preparados tradicionales en las boticas hacia laboratorios especializados y fábricas. Fue entonces cuando empezó la comercialización industrial de las medicinas.

Estos nuevos remedios que en gran medida eran los antiguos, pero modernizados e industrializados, prometían incontable beneficios a una población deficitaria en salud, diezmada por continuas epidemias, mal alimentada e ignorante. Y la enfermedad se hizo negocio. O como señala Puerto, "Los específicos, se quiera o no, tienen un componente económico imposible de ocultar" (2004: 38). El medicamento rebasa su carácter científico y 
deviene en objeto industrializado, sujeto a las leyes económicas de mercado y consumo; bajo esta naturaleza lucrativa, se alejan de lo científico y se anuncian con profusión en la prensa española. Se inicia entonces el carácter fraudulento de estos productos que tanto daño hicieron a la población, y también a la publicidad; aspectos ambos censurados, desde mediados del siglo XIX, por médicos de la época: "La Medicina no puede tolerar ni aprobar tantos anuncios, tantos prospectos, tantos folletos, tantos librotes de ignorancia, de engaño, de especulación y de farsa médica: y por tanto los reprueba de la manera más solemne, como perjudiciales á la salud" (Codinach, 1854: 130).

Lo paradójico es que hace casi ciento cincuenta años la Ley de Sanidad de 1855 y las Ordenanzas de Farmacia de 1860 habían prohibido la elaboración de los específicos. A mayor abundamiento, las ordenanzas de 1860 vedaban la publicidad en prensa que no fuera del sector profesional. La medida fue resultado de varios factores. Primero, el carácter fraudulento que muchos de ellos tenía; segundo, su elaboración por individuos que no pertenecían a la profesión farmacéutica y, tercero, el temor de muchos boticarios españoles a la competencia y, en consecuencia, a la reducción de beneficios.

Aunque la legislación no se cumplió y las empresas extranjeras establecidas en España siguieron con sus actividades, los núcleos industriales de Madrid, Barcelona y Aragón sufrieron graves pérdidas e incluso algunos desaparecieron. Los otros beneficiados por esta ley fueron los boticarios, que en sus pequeños comercios siguieron preparando específicos: "Cuando un boticario pone en su botica de gran lujo, qué es lo que con ello se propone? fácil es de sospechar que quiere llamarse la atención [...], el boticario que anuncia, ó de cualquier modo publica medicamentos, da lugar á pensar á las gentes sencillas, que él es mejor boticario que los otros que no las publican" (Codinach, 1854: 104).

La vertiente económica se impuso siempre, tanto para los empresarios/anunciantes de estos artículos, como para los soportes publicitarios a los que prescindir de la mayor partida de sus ingresos suponía una notable pérdida.

Así mismo, y como decíamos antes, la publicidad del sector Salud representa el 34,82\%. De ésta, el $81,44 \%$ son anuncios de productos medicinales; el 13,79\%, de servicios -médicos, dentistas, curanderos-, y el 2,70\% de establecimientos. Pero además, en la publicidad de productos, se observa cómo, hasta 1899, el 59,17\% de los anuncios eran de procedencia española; el 20,88\%, francesa; el 2,97\%, norteamericana y el 15,16\% desconocida. 


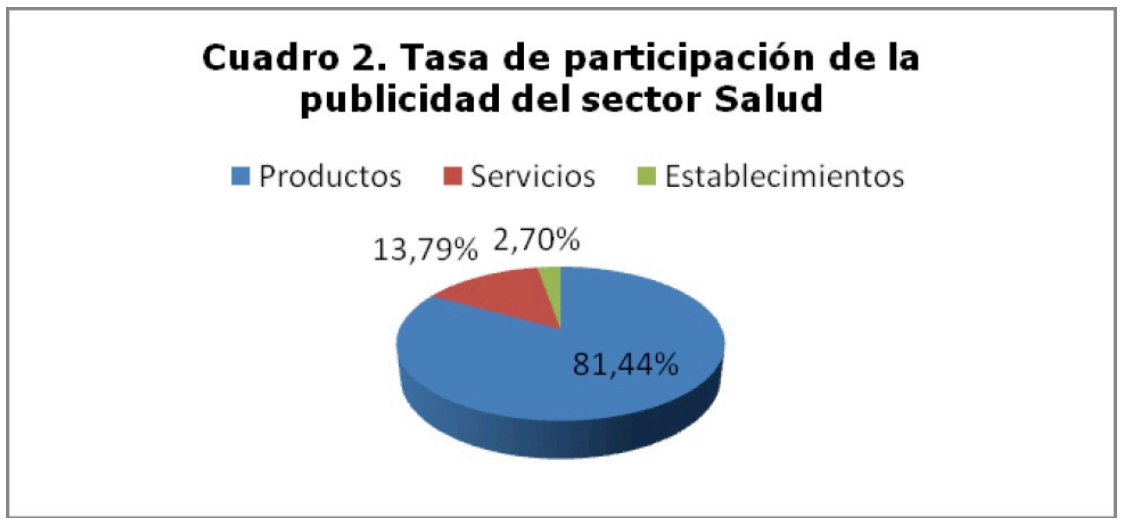

Elaboración propia a partir del corpus de anuncios de Blanco y Negro (1891-1899).

Estas cifras reflejan la gran concurrencia, y por tanto competencia, de productores en este sector, el mantenimiento de la producción artesanal en las boticas, la presencia (y ventaja) de los productos extranjeros y el deterioro de la naciente industria española del medicamento. Sin ir más lejos, la partida más abundante de los artículos españoles corresponde a las aguas medicinales, estos es, a artículos de sencilla o nula elaboración.

\subsection{Publicidad de productos ${ }^{3}$}

El rasgo más llamativo de los específicos es el de la diversidad de formas: aguas, bálsamos, jabones, jarabes purgativos, pomadas, zarzaparrillas, tónicos, granos de salud, pastas de dientes, granulados, polvos, lociones, crecepelos, elixires... Cualquier enfermedad era susceptible de ser aliviada, e incluso erradicada, con estos productos milagrosos. Su lectura nos proporciona un curioso y completo tratado de los padecimientos más comunes de la época. A grandes rasgos, las formas galénicas y marcas más anunciadas, agrupadas por categorías, fueron las siguientes:

- Aguas medicinales. Aparte de la reputada agua de azahar La Giralda, se comercializaban otras como Marmolejo, Carabaña (profusamente anunciada también en Nuevo Mundo) y la de Rubinat-Llorach. La primera se preparaba "echando [en] un vaso de agua fresca azucarada una cucharada" (13-9-1891: 2). El agua Marmolejo combatía "todos los padecimientos del ESTÓMAGO, HÍGADO, BAZO, RIÑONES Y VÍAS URINARIAS". A dichos remedios, le añadía una clara ventaja diferencial que residía en el envase: "Únicas aguas [...] en botellas especiales con tapón mecánico para su mejor conservación y mayor economía de los enfermos" (26-7-1891: 2).

- El jarabe fue otra de las presentaciones habituales. Había fórmulas para todos los males: para catarros y afecciones de las vías respiratorias, el jarabe pectoral de Alcober o el de Bromoformo del Dr. Fernández Gómez; para expulsar los gusanos intestinales, el jarabe vermífugo del Dr. Blas; para exonerar el vientre, había abundantes purgantes como La Margarita en Loeches.

${ }^{3}$ Dado que las referencias de todos los anuncios son de Blanco y Negro, omitimos explicitarlo. 


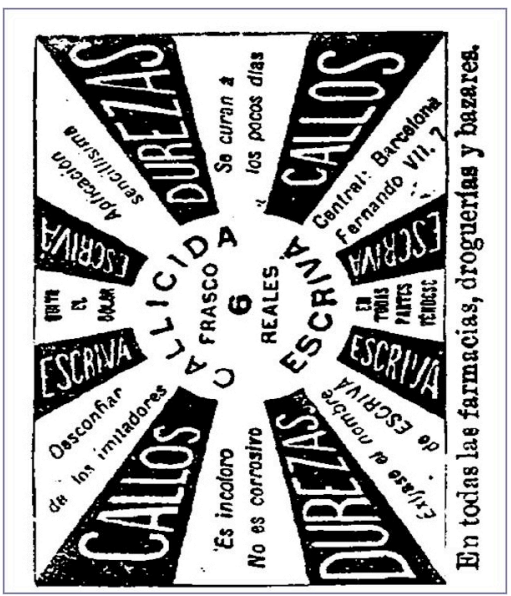

Figura 1. La disposición vertical del anuncio es la original. Blanco y Negro, 17-8-1895.

- Bajo la forma de pastillas, se preparaban las balsámicas de Morelló y las pectorales del Dr. Andreu con las que "casi siempre desaparece la TOS antes de concluir la primera caja" (111-1896: 22). Los veritables Grains de Santé du docteur Franck aliviaban estreñimientos, jaquecas y congestiones (8-1-1898: 17). De mayor espectro era la Cascarina Leprince, que se enviaba gratis a "toda persona que [facilitara] sus señas" (8-1-1898: 16).

- También los callicidas fueron populares. Entre los de mayor presencia publicitaria, los de Xifra, Lluch y Escrivá. Cierta originalidad muestra el último, quizá en un afán de alejarse de la monotonía tan frecuente en estos anuncios de finales de siglo. Como se aprecia en la imagen (fig. 1), a la ruptura de la linealidad del texto se le suma el juego de blancos y negros y las repeticiones, tanto del nombre de su creador -Escrivá-, como de los males que remediaba (callos y durezas).

- Aunque son dos los anunciantes de pasta de dientes - Licor del Polo de Orive y Pâte Dentifrice Glycerine-, con propósito terapéutico sólo lo hace el primero: "BOCAS Y MUELAS [...]. LICOR DEL POLO DE ORIVE, que calma los DOLORES DE MUELAS al descuidado que no sigue la HIGIENE DE LA BOCA" (22-11-1891: 2). Es ésta una de las escasas menciones al tema de la higiene; grosso modo, las apelaciones de los anuncios se orientan abiertamente a la cura de enfermedades, antes que a actitudes profilácticas.

- Los tónicos representan una de las especialidades infalibles para restablecer la salud quebradiza. La emulsión Forcada estimulaba "el desarrollo de carnes y huesos" (Nuevo Mundo, 2-11-1898: 17). De aparición constante durante todo el período, fue el Hierro Bravais, cuya publicidad se basó en un pequeño recuadro, en que destacaba en caja alta y negrita un escueto mensaje; se dirigía al bello sexo, que, junto a niños, mujeres en cinta y nodrizas, parecían sufrir de corta salud; destinatarios éstos también del Vino de Quina Laroshe de procedencia francesa, al igual que Ossian Henry, que decía ser el mejor y más eficaz y, como los otros, curaba la "Clorosis, la Anemia, [...], las constituciones débiles" (275-1893: 21). 
La competencia fue Aperital, Bitter o vino tónico, que "promovía el apetito, la digestión, el sueño y la salud" (11-1-1896: 3). Se trata, salvando las distancias, de un anuncio moderno, con un dibujo sencillo y legible muy alejado de los que llenaban la publicidad de específicos; un dibujo cuya importancia reside en destacar, junto al producto, la satisfacción que traslucen la sonrisa y el gesto distendido del personaje (fig. 2).

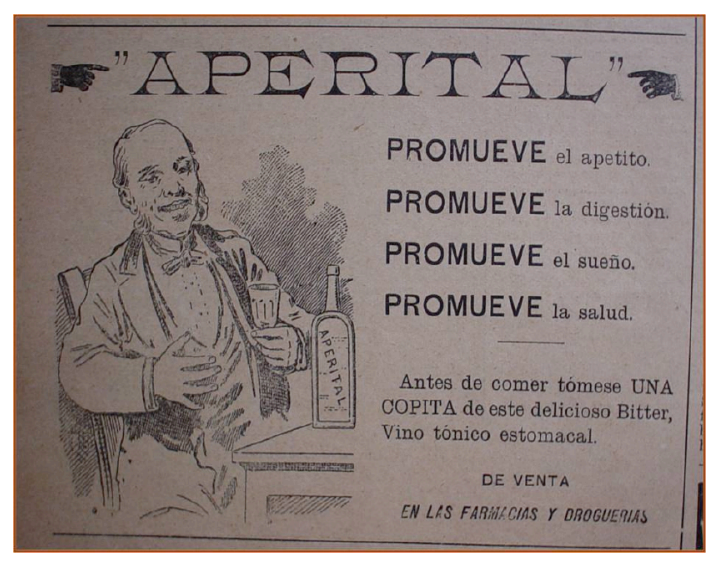

Figura 2. Blanco y Negro, 1896, no 245, p. 3.

Nos hallamos ante un nombre de marca de evidente modernidad. Aperitivo, en su primera acepción, es un "Medicamento o cualquier cosa de comer o beber que se toma para excitar el apetito" (Moliner, 1990: 11). Si atendemos a su etimología, al significado del sustantivo Aperitivo, se le añaden los de sus elementos de composición: "Medicamento/Aperitivo que abre con abundancia el apetito". La reiteración como estrategia: la información redundante en la publicidad (Rey, 1997: 20). Acierto en el nombre que gana frente al de otros específicos, donde se empleaba la forma galénica seguida del nombre de su creador: granos de salud del Dr. Franck, zarzaparrilla del Dr. Simón, jarabe vermífugo del Dr. Blas...

De obligada mención, por sus sorprendentes propiedades, son medicamentos como Cigarrillos Espic, que curaban asma y catarros. Quedan también restos de las excelentes propiedades que se le atribuían al café y al té (Elliot, 1962:36); Glandario era el "café de salud recomendado por todas las eminencias médicas" (16-4-1898: 21), y el té purgante de Chambard, "el más eficaz de los purgativos" (22-11-1891: 20). Excepcional por haberlo hallado sólo en Nuevo Mundo es el anuncio del Tónico-Genitales del Dr.Morales "célebres píldoras para la completa y segura curación de la EXTENUACIÓN" (20-12-1899: 18).

\subsection{Publicidad de servicios}

Al conjunto tan fértil de productos, se le añaden algunas muestras de la publicidad de los servicios que se ofrecían, y donde se aprecian cuatro tipos de prestaciones: balnearios, dispensarios, odontología y asistencia médica.

En el primer grupo, destacan los Baños de Trillo y los de Alceda-Termal de Santander, que decían poseer un caudal de 3.640.240 litros diarios. Los dispensarios podían adoptar diversas 
formas y denominaciones: Gabinete dental, Gabinete médico-mecánico para el tratamiento de hernias, Clínica del Dr. Bercero, Instituto Brown-Sequard. A tenor de la publicidad examinada, podemos pensar que la odontológica era una de las más requeridas: Boniquet, Casto Carrasco, Guijosa, Silberio Villarjubin, Juliá y Hubert. En general, eran escuetos avisos de intención informativa.

En cuanto a la publicidad de asistencia médica, la más copiosa se circunscribe a dos anunciantes, el Dr. Audet. y el Dr. Garrido. El primero mostraba, generalmente, la relación y descripción de los específicos que comercializaba. La publicidad del Dr. Garrido -figura destacada del Gremio de Anunciantes (1880) - fue una de las más espectaculares (Bravo, 1985: 77). De gran audacia, abarcó desde ingeniosas maquetaciones (fig. 3) hasta completos tratados pseudofilosóficos. Al repasar la prensa de finales del siglo XIX, es imposible no reparar en sus espectaculares anuncios de una plana o en sus sobrios comunicados. Utilizó variados formatos publicitarios - comparativos, testimoniales-y estilos tipográficos.

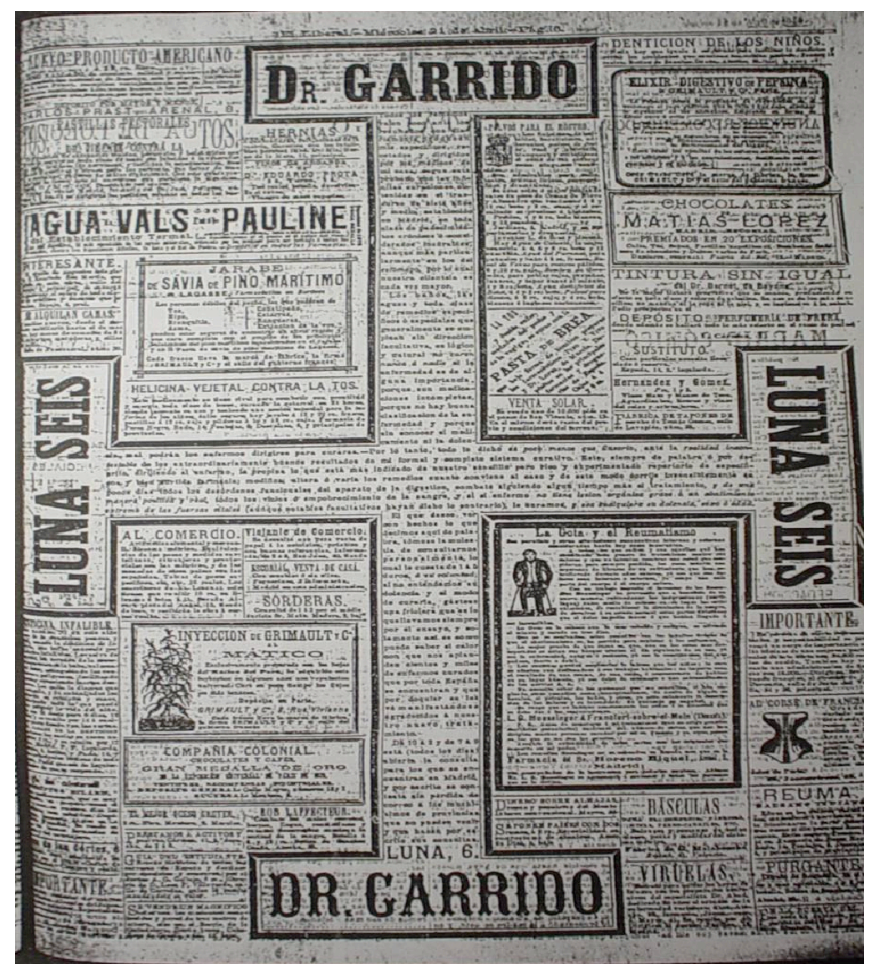

Figura 3. El Liberal, 21 de abril 1880.

\subsection{Publicidad de establecimientos}

La publicidad de establecimientos (figuras 4-5) apenas representa un 2,70\% del total de la publicidad del sector Salud. Prácticamente, casi todos los anuncios pertenecen a farmacias que se identifican a través del nombre de sus propietarios: Boix, Tribaldos, hijos de Carlos Ulzurrun; aunque se da algún caso inusual en cuanto al nombre, como la Farmacia Económica, en general, se trata de una publicidad carente de elementos ornamentales, así 
como de mensajes persuasivos, que no hace sino ofrecer los datos de localización del establecimiento. Una excepción es la ortopedia de Eduardo Cort, profesor de ortopedia y especialista en la construcción de bragueros y aparatos ortopédicos, quien incluía en sus anuncios imágenes de los productos que él mismo construía.
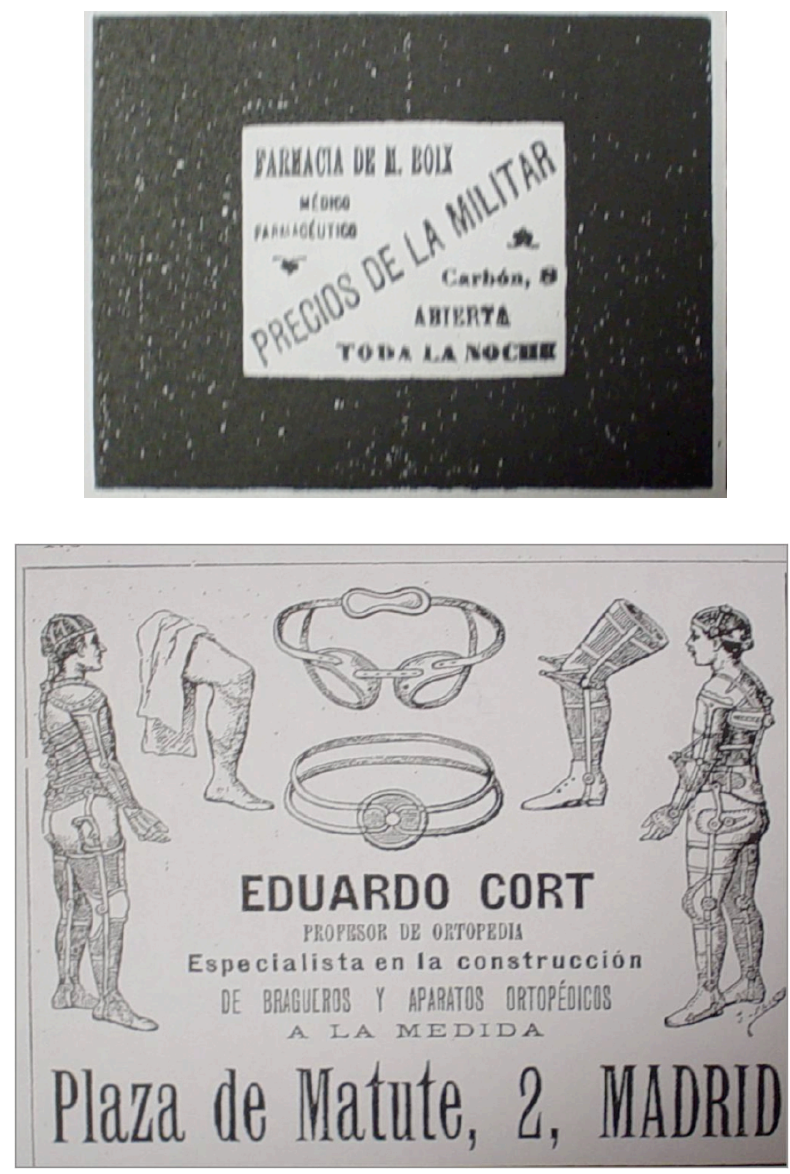

Figuras 4-5. Farmacia Boix (1893) y Ortopedia de E. Cort (1893). Blanco y Negro.

\section{Conclusiones}

La publicidad del sector de la salud es la más copiosa en la revista Blanco y Negro (años 1891-1899), con un peso del 34,82\% sobre un total de 1366 anuncios. Así mismo, la revisión de los ejemplares de Nuevo Mundo pone de manifiesto la paulatina introducción de estos anuncios desde su fundación en 1894 hasta 1899, siendo los dos últimos años, y en particular los editados en el último trimestre, los que registran un mayor número de anuncios en general y de medicinas patentadas en particular ${ }^{4}$, revelando también que abundantes anuncios eran de idéntica factura y composición en los dos semanarios; lo que significa corroborar la hipótesis de la que parte la investigación: en España, y al igual que

\footnotetext{
${ }^{4}$ Véanse, por ejemplo, los siguientes ejemplares: 26-10-1898, 21-12-1898, 28-12-1898, 31-5-1899, 57-1899, 20-9-1899, 11-10-1899, 29-11-1899, 20-12-1899.
} 
sucedió en los países que primero se industrializaron, la publicidad de específicos fue la más abundante y vital para el desarrollo de la prensa y para la evolución de la actividad publicitaria.

Por otra parte, no es descabellado establecer una correlación entre la abundancia de medicamentos milagrosos y la economía española, de crecimiento lento, de escaso desarrollo industrial y castigada por repetidas crisis de subsistencia y epidemias. Razones que provocaron la permanencia del sistema demográfico tradicional hasta 1900: los numerosos anuncios de medicinas patentadas, más próximas al milagro y a lo mágico que a la ciencia, no hacen sino reflejar las necesidades de una población desnutrida y enferma; una población que buscaba salud, porque carecía de ella. La publicidad de la salud, al igual que los médicos higienistas, evidenciaba el insuficiente grado de bienestar de la España de finales del siglo XIX.

Así mismo, la agrupación en tres categorías de los anuncios analizados - productos, servicios y establecimientos-, evidencia, primero, la gran importancia de los productos $(81,44 \%)$ y su rica variedad de formas galénicas y marcas y, segundo, el escaso peso de los otros dos que, sobre todo, están representados por farmacias y gabinetes médicos y balnearios.

Por último, es necesario subrayar la trascendencia que esta publicidad tuvo para la reactivación de la prensa, en la que Blanco y Negro fue pionera, y no sólo por su planteamiento comercial al contratar anuncios desde su origen, sino porque demostró que los ingresos por esta partida presupuestaria eran rentables, pero también valiosos para que la prensa abandonara su excesiva sujeción a las vicisitudes e ideologías políticas al uso - causa de la fugacidad y precariedad de las cabeceras-, e iniciara el paso hacia su conformación moderna. 


\section{REFERENCIAS BIBLIOGRÁFICAS}

AlCAide GonzÁlez, R. (1999a): "Las publicaciones sobre higienismo en España durante el período 1736-1939: un estudio bibliométrico", en Scripta Nova. Revista Electrónica de Geografía y Ciencias Sociales, no 37, pp. 1-49.

AlCAide GonzÁlez, R. (1999b): "La introducción y el desarrollo del higienismo en España durante el siglo XIX. Precursores, continuadores y marco legal de un proyecto científico y social, en Scripta Nova. Revista Electrónica de Geografía y Ciencias Sociales, no 50, pp. 1-48.

Altabella, J. (1963): "La Correspondencia de España. Notas para una historia de la publicidad", en IP: Información de la Publicidad, no 7, pp. 15-18.

BLANCO Y NEGRO. Años 1891-1899.

Bravo, Julián (1985): "El Gremio de Anunciantes de 1880. Notas apresuradas que me gustaría dedicar a la A.E.A. en su XX Aniversario", en Campaña, Extra/Junio, pp. 74-80.

CARRERAS, Albert (1997): "La industrialización: una perspectiva a largo plazo", en Papeles de Economía Española, 73, pp. 35-60.

CASTILLO, Santiago (1975): "La prensa diaria de Madrid: notas para el análisis de las estadísticas del timbre (1873-1887)", en Prensa y sociedad en España (1820-1936), Tuñón de Lara, Elorza y Pérez Ledesma (editores), Madrid, Edicusa, pp. 149-198.

CODINACH (1854): Una medicina nueva para curar la manía de los publicadores, vendedores y compradores de medicinas llamadas específicas, Barcelona, Imprenta de A. Verdeguer.

CHECA, Antonio (2007): Historia de la publicidad, La Coruña, Netbiblo.

EguizÁBAL, Raúl (1998): Historia de la publicidad, Madrid, Eresma\&Celeste Ediciones.

ElLIOT, Blanche (1962): A History of English Advertising, London, Business Publications.

EsCUDERo, Antonio y SIMÓN, Hipólito (2003): "El bienestar en España: una perspectiva de largo plazo, 1850-1991", en Revista de Historia Económica, Año XXI, no 3, pp. 525-565.

FERnÁNDEZ PoyATOS, Ma D. (2006): Orígenes y evolución de la publicidad en España. 1880-1936, Tesis doctoral, Alicante, Universidad Alicante.

García Gutiérrez, Rafael (1990): Publicidad farmacéutica. $1^{a}$ parte (1850-1950), Barcelona, Jornadas Profesionales, EFP y Parafarmacia.

IMPARCIAL, EL, 28-7-1885. 
MARTínez Carrión, J. (2000): "¿Fracaso industrial o atraso económico en la España del siglo XIX? El debate historiográfico en los últimos 25 años", en Aulahistoria social, no 5, pp. 72-87.

NADAL, Jordi (1975): El fracaso de la revolución industrial en España, 1814-1913, Barcelona, Ariel.

NorRIS, James D. (1990): Advertising and the Transformation of American Society, 1865-1920, New York, Greenwood Press.

NUEVO MUNDO. Años 1895-1899.

PÉRez RuIz, M.Á. (2001): La publicidad en España. Anunciantes, agencias y medios. 1850-1950, Madrid, Fragua editorial.

Prados de LA Escosura, L. (1988): De imperio a nación. Crecimiento económico y atraso en España (1780-1830), Madrid, Alianza.

PRAdos de LA Escosura, L. (1995): Spain's gross domestic product, 1850-1993: quantitative conjetures, Universidad Carlos III, Documento de Trabajo 9506, febrero.

PUERTO, F. Javier (2004): El medicamento en el escaparate: la publicidad farmacéutica en España, una aproximación histórico-literaria, Barcelona, Fundación Uriach, colección histórica de ciencias de la salud, nº 8.

REY, Juan (1997): "El iconismo gráfico en la escritura publicitaria", en Questiones Publicitarias, no 6, en http://www.maecei.es/pdf/n6/articulos/el_iconismo_ grafico_en_la_escriturapubliciatria.pdf (consultado: 13/02/2011).

SeOANe, Ma Cruz (1992): Historia del periodismo en España. 2. El siglo XIX, Madrid, Alianza Universidad Textos.

TORTELLA, Gabriel (1994): El desarrollo de la España contemporánea. Historia económica de los siglos XIX y XX, Madrid, Alianza Universidad.

[Recibido: 17 de marzo de 2011. Aceptado (con indicación de cambios): 19 de septiembre de 2011. Recepción del artículo corregido: 21 de septiembre de 2011.] 